\title{
pnmbalina
}

(8)

\section{Relendo Karl R. Popper}

Autor(es): $\quad$ Barata, Maria do Rosário Themudo

Publicado por: Imprensa da Universidade de Coimbra

URL

persistente: URI:http://hdl.handle.net/10316.2/30045

DOI: $\quad$ DOI:http://dx.doi.org/10.14195/978-989-26-0567-8_15

Accessed : $\quad$ 26-Apr-2023 12:28:34

A navegação consulta e descarregamento dos títulos inseridos nas Bibliotecas Digitais UC Digitalis, UC Pombalina e UC Impactum, pressupõem a aceitação plena e sem reservas dos Termos e Condições de Uso destas Bibliotecas Digitais, disponíveis em https://digitalis.uc.pt/pt-pt/termos.

Conforme exposto nos referidos Termos e Condições de Uso, o descarregamento de títulos de acesso restrito requer uma licença válida de autorização devendo o utilizador aceder ao(s) documento(s) a partir de um endereço de IP da instituição detentora da supramencionada licença.

Ao utilizador é apenas permitido o descarregamento para uso pessoal, pelo que o emprego do(s) título(s) descarregado(s) para outro fim, designadamente comercial, carece de autorização do respetivo autor ou editor da obra.

Na medida em que todas as obras da UC Digitalis se encontram protegidas pelo Código do Direito de Autor e Direitos Conexos e demais legislação aplicável, toda a cópia, parcial ou total, deste documento, nos casos em que é legalmente admitida, deverá conter ou fazer-se acompanhar por este aviso. 


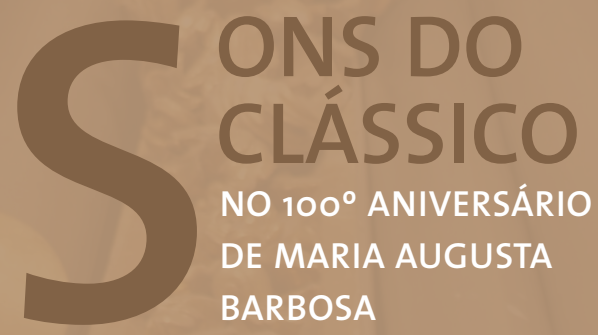

J. M. Pedrosa Cardoso

Margarida Lopes de Miranda COORDENAÇÃO 
Maria do Rosário Themudo Barata ${ }^{128}$

Universidade de Lisboa

\section{RELENDO KARL R. POPPER}

Um dos aspectos que me interessou particularmente na autobiografia intelectual de Karl Popper, cujo centenário se celebra este ano, foi o facto de, no discurso do pensamento, após o exame do processo de aprendizagem que caracteriza em três vertentes (no sentido do descobrimento ou formação dogmática de teorias, no sentido da aprendizagem por imitação e no sentido da aprendizagem por repetição ou prática, e que poderemos sintetizar em dois aspectos, a teorização e a crítica ou eliminação do erro), o filósofo sublinhar a importância que para ele revestiu a aproximação à Música.

Popper não acredita na aprendizagem por indução e defende que nunca existiu observação imparcial ou experiência passiva, pois que, como diz, há sempre o problema. Segundo as suas palavras, "a experiência é o resultado da exploração activa levada a cabo pelo organismo, da busca de regularidades ou invariantes", vincando que a hipótese deve ser prévia à observação e à percepção e que há expectações inatas, conhecimentos inatos latentes a serem activados por estímulos quando estamos comprometidos numa exploração activa. "Toda a aprendizagem é uma modificação (pode ser uma refutação) de algum conhecimento anterior, e assim, em última análise, de um conhecimento inato" (Karl R. Popper 1985: 69/70).

\footnotetext{
128 Em homenagem à Senhora Professora Doutora D. Maria Augusta Barbosa. Recordando, não só o magistério universitário que desenvolveu após o Doutoramento em Ciências Musicais na Alemanha - o primeiro doutoramento de um português nesta especialização - mas também a docência de História da Música no Conservatório Nacional de Lisboa. De ambas as circunstâncias a signatária preserva a riquíssima recordação do que usufruiu, pelo que as breves linhas que se seguem têm como propósito único o de manifestar o reconhecimento e a admiração por tudo o que deve à Homenageada. Páscoa de 2002.
} 
Estas posições não são de estranhar na filosofia essencialista e em todas as reflexões pós-kantianas, como também não surpreendem num retorno às matrizes do próprio pensamento grego, onde poderemos buscar as primeiras reflexões sobre a relação entre a música e o desenvolvimento do conhecimento. Mas hoje gostaria tão só de transmitir algumas reflexões acerca da comunicabilidade das artes.

Karl Popper refere o gosto pela música que era comum na família de sua mãe, a sua aprendizagem em tenros anos, a sua experiência como coralista na Paixão segundo S. Mateus de João Sebastião Bach, a amizade que o ligou desde sempre a Rudolf Serkin, bem como a Ernest Gombrich, ele, como sabemos, filho de uma aluna de Bruckner e casado com a pianista Ilse Heller e para quem o mundo das artes era um mundo multifacetado. Melhor dito, a Arte tem variadíssimos aspectos, qualia na expressão de Etienne Souriau, que se interrelacionam e se correspondem num mesmo processo de instauração.

Teremos de recordar que Viena de Áustria é, não só a sede do círculo lógico que marcou o século xx, mas uma das sedes europeias da música. Conservador no seu gosto musical, Popper inscreveu-se na Sociedade presidida por Arnold Schonberg, e que tinha como intenção divulgar a música contemporânea. Aí se familiarizou, não só com a música de Schonberg, mas também com a de Webern e de Alban Berg. E depois desta experiência voltou a dedicar atenção à música religiosa, também em Viena, e tornou-se cada vez mais admirador dos "clássicos".

Desse convívio musical colheu três princípios fundamentais que influenciaram, para sempre, as suas concepções (Karl R. Popper 1985: 73).

- as reflexões sobre o pensamento dogmático e crítico;

- a distinção entre o que considerou dois tipos de música, a música objectiva e a música subjectiva;

- a redução incomensurável que as ideias historicistas produzem na apreciação da música e das artes em geral.

Quanto ao primeiro ponto, o pensamento sobre a música levou-o a acentuar, mais do que a psicologia do descobrimento, a lógica do descobrimento, 
e a poder estudar não só a lógica do desenvolvimento da ciência grega, como a lógica da polifonia, ou seja, da harmonia musical ocidental. Neste sentido, a criação da música erudita ocidental é, para Popper, o facto mais original e milagroso da civilização ocidental, isto sem excluir a ciência: como, a partir de uma melodia, o coro humano desenvolveu o contraponto, em movimentos de vários sentidos mas num conjunto inter-relacionado, inventivo mas sem caos, e que é a característica da Harmonia.

A dogmática, a harmonia, a proposta científica terão em comum serem uma leitura que permite explorar a ordem dos mundos desconhecidos, criando regularidades e captando as já existentes. Qualquer destes exemplos fornece coordenadas. E, como diz, "além disso, uma grande obra de música (como uma grande teoria científica) é um cosmos imposto sobre o caos - nas suas tensões e harmonias inextinguíveis, inclusive para o seu criador" (Karl R. Popper 1985: 78).

Popper citava Kepler e falava nos pressupostos do conhecimento kantiano para sublinhar a logicidade do processo de conhecimento sobrepondo-se às considerações da psicologia do descobrimento.

A segunda questão dizia respeito ao que apontava como música subjectiva e música objectiva, o que mais tarde o leva a distinguir o Mundo 2 e o Mundo 3 na sua filosofia. Esta questão tinha começado por ser a tentativa de interpretar as diferenças entre a música de Bach e a música de Beethoven. Se bem que viesse, depois, a mitigar a diferença, não obstante não deixou de acreditar em que uma diferença essencial existia. Para Popper, Beethoven teria feito da música uma auto-expressão. Fidelio seria a mais emocionante expressão de fé de um homem, contra todo o desespero.

Isso não se passaria com João Sebastião Bach. Para além da apreciação das formas de criação artística dos dois grandes músicos, Karl Popper estabelecia uma apreciação global sobre a Arte em que não concordava, nem com a arte como produto do tempo e do lugar, nem com a arte como mera expressão ou auto-expressão do artista. Abordando, a este propósito, aspectos fundamentais de toda a estética e teoria da arte, Popper manifestava entender a Arte, não só como expressão subjectiva mas como referência (ao real ontologicamente falando) e como signo. A arte auto-expressão psicológica não lhe bastava. Havia a essencialidade da obra. O objectivo do 
verdadeiro artista seria, como o próprio diz, "a perfeição da obra” (Karl R. Popper 1985: 83).

Popper transmitia o que sentia no convívio com a obra musical de Bach: "Bach esquece-se de si próprio na sua obra, é um servidor da sua obra. Sem dúvida não deixa de imprimir a sua personalidade nela, isto é inevitável. Mas não era consciente às vezes, como era Beethoven, de que se estava exprimindo a si próprio e inclusive a seus humores. Por esta razão eu via cada um deles como representante de duas atitudes opostas com respeito à música" - e esta diferença poderia existir nas próprias peças religiosas dos dois compositores.

A questão seguinte seria a de saber se a estrutura de Bach é mais importante do que as rupturas dinâmicas e de que forma a música de Beethoven ou de outro compositor anota um comportamento diverso. Bach pretendia ensinar aos seus discípulos a composição, de forma clara e distinta, de maneira que os discípulos pudessem vir a desenvolver, mais tarde, as suas próprias ideias musicais. Onde caberia a emoção? Ela tem um lugar fundamental, e lembremos a profundíssima emoção da Paixão segundo S. Mateus, como inspiração e como julgamento, pelo próprio artista, da obra produzida. Mas essencialmente a música clássica ou erudita não é a que exprime as suas emoções em música, mas a que apresenta questões e problemas musicais, e os resolve.

E Popper voltava à questão já abordada: teria Beethoven sido o primeiro expressionista, porque compositor romântico?

Mas também a este propósito Karl Popper lembrava como Beethoven trabalhava, por vezes, versão atrás de versão, as suas ideias musicais (por exemplo, na Fantasia Coral e na Nona Sinfonia). E, na sua opinião, não fora o expressionismo a causa da decadência da música, mas a variedade de experiências formais desenvolvidas na época contemporânea, sem continuidade e sem sentido. Pois nada permite dizer que as artes progridem historicamente e que o progresso se dará quando um artista domina todos os conhecimentos do seu tempo.

Pode dar-se o caso de as novidades fazerem esquecer o adquirido, de as inovações formais não corresponderem à renovação da imaginação. Por isso, e estamos a focar o terceiro aspecto das reflexões de Popper, a visão historicista das artes será de banir, bem como a sobrevalorização dos aspectos 
de vanguarda. Alguns dos maiores artistas de todos os tempos não se preocuparam, nem procuraram, afirmar estilo próprio, ou moda. Bach, Mozart, Schubert, não pensaram nisso. Nem procuraram estar à moda. Portanto, o historicismo na Arte é um erro.

Estas observações de Karl Popper são estimulantes e oportunas. Antes de tudo o mais, no essencial, pelo que testemunham do enriquecimento intelectual que o convívio com a arte musical proporciona, colocando o debate das artes muito para além de emoções, modas, delírios de execução e de técnica, não rechaçando a emoção mas comprometendo-a com o entendimento, numa procura de sentido pleno e universal.

Seguindo os três passos do pensamento de Popper que referimos, no primeiro encontramos o sublinhado da lógica da invenção, segundo a qual melhor entenderemos a arte medieval, mas também a do tempo do classicismo e do barroco, sem cair na armadilha da dificuldade da distinção dos dois estilos, armadilha a que escaparam, entre outros, Victor Lucien Tapié e Pierre Chaunu que estudaram a época, a cultura e as artes, concluindo pela tensão lógica, intelectual e existencial da procura de ordem, sobrepondo-se aos estilos: o conteúdo dominando a forma, pois esta podia e devia ser dominada com toda a mestria. Se percebemos como artistas clássicos e barrocos coexistem na mesma época, pois lhes é comum algo de essencial para além do estilo diverso que adoptam, já há anos aprendíamos no Conservatório Nacional de Lisboa quão errado e incompleto seria classificarmos Bach "simplesmente" como compositor barroco: esqueceríamos a sua sabedoria de "ofício", a forma como desenvolveu a arte musical na senda das escolas de Viena e Mannheim, de seus mestres Reinken, Buxtehude, Pachelbel, escolas e mestres que tanto "explicam" Bach, como "explicarão" Haydn e Mozart, entre outros. Há a sequência lógica do desenvolvimento das ideias e das formas musicais, vocais e instrumentais, o labor continuado, a acção pedagógica que permitirá a liberdade do outro, numa procura universal de beleza, no aproveitamento da imaginação e das capacidades individuais, tendo como finalidade a obra. Afinal, não é ela, como diz Heidegger, o essencial?

A segunda reflexão é, também, extremamente interessante: a distinção entre música objectiva e música subjectiva. Certo é que o próprio Popper a matizou, pois, de outro modo, quereria parecer que desprezava em absoluto 
as diferenças culturais entre épocas e o próprio desenvolvimento das formas musicais, para não falar na inspiração e nos temperamentos; mas aqui poderíamos também aludir ao sentido diferencial que tem a palavra no emprego que dela fez Bach, por exemplo, no Cravo Bem Temperado. Estas reflexões sugeriram-me a necessidade de aludir ao trabalho de heurística e hermenêutica prévio a qualquer interpretação musical e quão necessário ele se patenteia quando se assiste a "fantasiosas" leituras e "intempestivas" execuções (mais sensível, o erro já foi corrigido nas interpretações de Chopin e Debussy, mas o perigo espreita qualquer um. E não falo na música para vozes). Cabe ao intérprete, na arte musical, como no teatro e na dança, dar corpo à obra. E como se complexifica a questão da execução! Cabe ao intérprete dar a versão do autor, ou a sua própria? Qual a relação do artista e da obra?

Este aspecto relaciona-se com o terceiro: o papel da técnica no desenvolvimento das artes, a importância do domínio das técnicas específicas de cada arte. O domínio do quadro técnico específico é essencial para cada artista. Já assim os artistas do renascimento e do maneirismo consideravam, mas estes últimos pensaram poder garantir, com este aspecto, a perenidade da qualidade estética e do estilo, e enganaram-se pois lhes faltou a consciência da historicidade de que outros abusam. A Arte procura o Eterno sob formas mutáveis, seguirá o seu caminho próprio e não se confundirá com a Filosofia, onde terminaria. Mas também não se confundirá com a História e com os recursos do tempo e do lugar. A qualidade da execução das Sonatas de Beethoven não residirá, apenas ou principalmente, na rapidez dos Allegro ou noutras capacidades técnicas do executante. Se bem que o verismo tenha os seus perigos, a ausência do referencial ao tempo e ao lugar da criação artística é outro logro. E antes de qualquer "execução" há que compreender o mais completamente possível o projecto do autor.

Ora, para isso há que conhecer a forma. Tanto na música como nas artes em geral, apesar dos excessos criticados ao formalismo, há noções fundamentais de Forma a preservar, e, no campo musical, ideias melódicas e opções harmónicas a desenvolver logicamente e a completar. A apreciação das artes não se poderá resolver tão só pela filosofia nem só pela historcidade, mas pela busca da essência do problema e da arte que é, ela mesma problema, como manifestação e "des-ocultação" do Ser. A historicidade não explica a 
melhoria das artes, da mesma forma como a Arte não deverá aceitar qualquer compromisso que represente um reducionismo em relação à sua essência e finalidade. Afinal, atingir o Ser e o Universal. E, como concluiria o Hípias, eis o que é difícil.

\section{Bibliografia}

Karl R. Popper (1985) Búsqueda sin término. Una autobiografia intelectual, Trad. do original de 1974 de Carmen Garcia Trevijano, $1^{\text {a }}$ ed. 1977, $1^{\text {a }}$ reimp. 1985, Madrid, Editorial Tecnos, S.A. 